\title{
Review of A Tale of Seven Elements
}

\section{Robert E. Buntrock*}

Buntrock Associates, Orono, Maine 04473, United States

A Tale of Seven Elements, by Eric Scerri. Oxford University Press: New York, 2013. ix + 177. ISBN 978-0195391312 (hardcover). \$19.99

$\mathrm{P}$ er the author's introduction, the periodic table, always a favorite among chemists (including this reviewer and the Book and Media Reviews editor), currently has a heightened awareness in the public eye. "Alternative" periodic tables abound. In addition to books aimed at scientists, ${ }^{1-4}$ at least two books on the periodic table and the elements aimed at general audiences have recently been published. ${ }^{5-7}$ In A Tale of Seven Elements, Scerri expands his coverage of elements in his previous book ${ }^{1}$ to cover seven "missing elements". These elements are the "infra-uranium" elements (as opposed to transuranium elements), the last to be discovered among the first 92 elements.

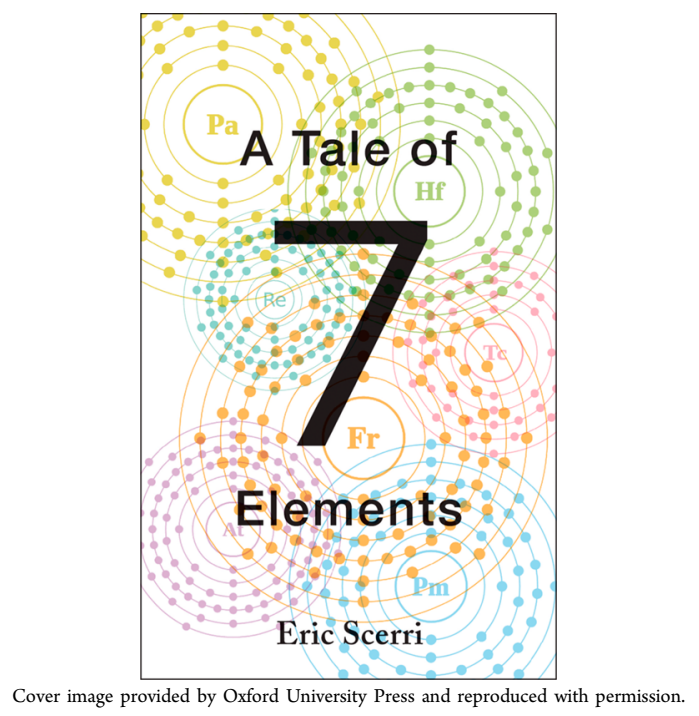

The introduction covers a wealth of topics, including disputes on scientific priority, both scientific and sociological, answering the question of what constitutes priority of elemental discovery, and how these concepts pertain to these seven elements. As a matter of interest, five of the elements are radioactive, and several were discovered by women.

The first chapter covers the development of the periodic table and a discussion of priorities. As with discovery of the elements themselves, the scientist given credit for the discovery is not necessarily the first, but the one who made the best use of the discovery. In this case, Mendeleev and his predictions win out and a box score of his predictions (the "eka" elements) is given. Throughout the book, the personalities of the scientists and detailed accounts of their work are presented.

Chapter 2 is titled "Invasion of the Periodic Table by Physics". Concepts and scientists are described, including the electron, X-rays, isotopes, electronic structure, Ernest Rutherford, and Henry Moseley. Of course, Moseley's discovery of $Z$, the atomic number, finally codified further progress and description of the periodic table.

Chapters 3-9 are devoted to detailed descriptions of the discovery of the elements filling the seven "holes" in Moseley's table, in order of their discovery. The often-torturous path of discovery is recounted, including the scientists involved, their personal histories, and the disputes, some of which were quite rancorous and even nationalistic. Also described are their predictability by Mendeleev, their chemistry, and select applications. The elements are protactinium $(Z=91)$, hafnium $(Z=72)$, rhenium $(Z=75)$, technetium $(Z=43)$, francium $(Z$ $=87)$, astatine $(Z=85)$, and promethium $(Z=61)$. The last chapter covers the transuranium elements, $Z=93$ and up, including their syntheses, disputes, and chemistry.

The book has extensive notes, a bibliography, author index and index. A Tale of Seven Elements is an excellent narrative and the value of narratives in science and science education is stressed. I highly recommend this book to students and their teachers, scientists, and the interested public.

\section{AUTHOR INFORMATION}

Corresponding Author

*E-mail: : buntrock16@roadrunner.com.

\section{REFERENCES}

(1) Scerri, E. The Periodic Table, Its Story and Its Significance; Oxford University Press: New York, 2007. Reviewed in J. Chem. Educ. 2007, 84 (4), 598.

(2) Emsley, J. The Elements, 3rd ed.; Clarendon Press: Oxford, U.K., 1998.

(3) Emsley, J. The A-Z of the Elements; Oxford University Press: New York, 2001.

(4) Stwertka, A. Guide to the Elements; Oxford University Press: New York, 1997. Reviewed in J. Chem. Educ. 1997, 74 (6), 627.

(5) Gray, T. The Elements: A Visual Exploration of Every Known Atom in the Universe; Workman Publishing Co.: New York, 2009. Reviewed in J. Chem. Educ. 2009, 86 (12), 1374.

(6) Kean, S. The Disappearing Spoon; Little, Brown, \& Co.: New York, 2012. Reviewed in J. Chem. Educ. 2011, 88 (2), 145-145.

(7) Aldersey-Williams, H. Periodic Tales; Penguin Viking: London, 2011. Reviewed in J. Chem. Educ.. 2011, 88 (12), 1605-1606. 